\title{
The Influence of Heating Temperature and Concentration Sodium Bisulfite Into Amilosa Content of the Extraction Starch Hipocotyl Bruguiera gymnorrhiza (L.) Lamk
}

Melkhianus H. Pentury

Faculty of Fisheries and Marine Sciences, University of Brawijaya, Malang, Indonesia

E-mail: meckypentury@gmail.com

Happy Nursyam

Faculty of Fisheries and Marine Sciences, University of Brawijaya, Malang, Indonesia

Nuddin Harahap

Faculty of Marine Sciences and Fisheries, University of Hasanuddin, Indonesia

Soemarno

Faculty of Agricultural, University of Muhammadyah Makassar, South Sulawesi, Indonesia

Received: March 20, 2014 Accepted: April 28, 2014 Published: May 8, 2014

Doi: 10.5296/jab.v2i2.5598 URL: http://dx.doi.org/10.5296/jab.v2i2.5598

\begin{abstract}
Hipocotyl Bruguiera gymnorrhiza High carbohydrate, but in Indonesia has not been exploited and developed, this is an alternative hypocotyl development for manufacturing starch as food ingredients industry. In addition to looking for new sources of starch for the modern food industry, also need to know the functional properties of starch. It aims to facilitate the diversification of the use of starch hypocotyl Bruguiera gymnorrhiza in various food industries. The purpose of this study was to determine the effect of sodium bisulfite solution concentration and temperature of heating and the interaction against best quality starch. In this study, the concentration of sodium bisulfite and heating temperature as a variable is changed, while the fixed variables are time and temperature of drying. The study was
\end{abstract}




\section{Macrothink}

conducted using a completely randomized factorial design with three replications with 2 factors that $\mathrm{NaHSO}_{3}$ concentration of $0.10 \%, 0.20 \%, 0.25 \%$ and $0.40 \%$ and heating temperature $40{ }^{\circ} \mathrm{C}, 50{ }^{\circ} \mathrm{C}$ and $6{ }^{\circ} \mathrm{C}$. Verse data processing using SPSS 16.0. Test parameters namely amylose content, solubility, viscosity, reducing sugar and starch content. The best treatment was determined using the method of De Garmo. These results indicate that treatment factors temperature and concentration on the extraction of starch hipocotyl Bruguiera gymnorrhiza significant effect $(\mathrm{P}<0.01)$ of the amylose content, starch content, viscosity, solubility and reduced sugar. Interaction heating temperature and concentration also had a significant effect on amylose content, starch content, viscosity, solubility and reduced sugar. Treatment with a heating temperature of $60{ }^{\circ} \mathrm{C}$ and the concentration of $0.25 \%$ for 5 minutes is the best treatment result was $19,58 \%$ amylose content, starch content of $65.00 \%$, $520.33 \mathrm{cP}$ viscosity, solubility and reducing sugar $91.99 \% 0.27 \%$.

Keywords: Bruguiera gymnorrhiza, extraction, sodium bisulfite, amylase 


\section{Introduction}

Utilization hipocotyl Bruguiera gymnorrhiza for processed food has been limited to flour naturally without modern treatment methods. To increase the economic value hipokotil Bruguiera gymnorrhiza needed a better processing methods (Wanma, 2007). Hipokotil Bruguiera gymnorrhiza have a high carbohydrate content (Fortuna, 2005; Sadana, 2007; Purnobasuky, 2012) and a high starch content (Pentury, 2009). Starch is an important nutrient in the daily diet, and the development needs of the world starch by the modern food industry is already attracting businesses to identify new sources of polysaccharides (Ancona et al., 2004). Greatest starch content found in green fruits and ripe yet, reaching $70 \%$ on dry weight basis. Based on the facts above, Hipokotyle Bruguiera gymnorrhiza starch can be used as an alternative source other than grasses (corn, wheat, and rice).

Bruguiera gymnorrhiza often found in almost all regions of Indonesia. However, beneficiaries are limited to ecological function. Endurance hipocotyl storage Bruguiera gymnorrhiza certainly be brief, and should be a product that is durable in terms of nutritional value, variety and durability of storage utilization. Therefore, it is necessary to develop the production of starch manufacture Bruguiera gymnorrhiza and studies about the nutritional value and functional properties such as amylose content, solubility, viscosity reduction and sugar as a reference in producing a meal. In addition, by making the starch Bruguiera gymnorrhiza starch can be stored longer and avoid decay. Separation Methods Bruguiera gymnorrhiza starch in this study using the method suggested by Waliszewski, (2003), namely the manufacture of flour Bruguiera gymnorrhiza suspension and distilled water and sodium bisulfite solution, and then dispersed over a specified time.

The benefits of this research are expected to: be known concentration of the solution and the proper warm temperature, so as to optimize the quality of starch produced hipocotyl Bruguiera gymnorrhiza. And develop potential use Bruguiera gymnorrhiza starch as raw material for the food industry. And the purpose of this study was to determine the effect of sodium bisulfite solution concentration, heating temperature and their interaction on the quality of starch on starch extraction Bruguiera gymnorrhiza order to obtain the best quality starch.

\section{Materials and Methods}

\subsection{Materials}

Material for the starch mangrove hipocotyl Bruguiera gymnorrhiza obtained from Bay District Kotania Piru West Seram regency Maluku province. While the chemicals used are sodium bisulfite $\left(\mathrm{NaHSO}_{3}\right)$ (pa). The raw material for analysis is protelium ether solvent $\mathrm{H}_{2} \mathrm{SO}_{4}, \mathrm{HCl} 25 \%, \mathrm{H}_{3} \mathrm{BO}_{3}$, phenolphtalein indicator, the indicator methyl blue, alcohol 10\%, $45 \% \mathrm{NaOH}$, nelson reagents, reagent arsenomolybdat, sodium tetraborate, $38 \%$ formaldehyde, methanol, ethanol $80 \%$, Folin reagent, $\mathrm{Na}_{2} \mathrm{CO}_{3}$, Lowry reagents and distilled water (pa). The equipment used in the extraction of starch is a tool Bruguiera gymnorrhiza flouring and 100 mesh sieve, dryer cabinet, Analytical Scales, blenders and equipment glass for analysis. 


\subsection{Methods}

This research was conducted at the Laboratory of Fishery Product Technology Faculty of Fisheries and Marine Sciences UB Malang, method used in this study is an experimental method, first hipocotyl Bruguiera gymnorrhiza peeled, cleaned and cut into small pieces the size of $<0.5 \mathrm{~cm}$ and then do the removal tannin with water immersion for 72 hours, with a change of water every 6 hours. After that the extraction of starch in the wet with heat treatment pieces hipocotyl Bruguiera gymnorrhiza temperature of $40{ }^{\circ} \mathrm{C}, 50{ }^{\circ} \mathrm{C}$ and $60{ }^{\circ} \mathrm{C}$ (the temperature is not maintained) in a solution of sodium bisulfite at a concentration of $0: 10 \mathrm{~g} / \mathrm{l}$; 0:20 g/l, $0.25 \mathrm{~g} / 1$ and $0.40 \mathrm{~g} / 1$ (1:2) for 5 minutes then add distilled water (1:2) for extraction (AACC method ekstrkasi modification., 1983) used Waliszewski (2003). Test parameters, namely, starch content, amylose content, solubility, viscosity and reducing sugar. Then the best treatment is determined using the weighted index of effectiveness (De Garmo et al., 1984).

\subsection{Analysis Procedure}

Analytical procedures characterize the physicochemical properties of starch mangrove cover analysis Starch, amylose, solubility, viscosity and reducing sugar. Analytical procedures starch hydrolysis using the Direct Method; AOAC, 1999 and amylose analysis procedure using the modified method Juliano, (1971). Spectrophotometry. Sugar reduction using reducing sugar analysis by the Somogyi-Nelson method (AOAC, 1990). Solubility and viscosity using gravimetric techniques using Rotational Viscometer, which is to get the value of the viscosity by measuring the twisting force a cylindrical rotor (spindle) were dipped into the sample.

And to test the effectiveness of determining the best treatment is determined by the effectiveness of the weighted index method (DeGarmo et al., 1984). This method is based on the following procedure: Variables are sorted by priority and contribution to results. Giving weight to the value of each variable (BV) based on contribution to the relative numbers $0-1$. The weight is different depending on the interests of each of the variables that the results obtained as a result of treatment. Weight of normal $(\mathrm{BN})$ was determined from each variable by dividing the weight of the variable (BV) with the sum of all weights of variables. Grouping variables were analyzed from two groups: a) Group A, consisting of variables average the bigger the better (the desired product treated), b) Group B is the group's growing increasingly ugly average (not desired). Then set the value of effectiveness (Ne) of each variable, using the formula:

\section{Treatment value - worst value}

Best value - worst value

For variable with mean the bigger the better, the lowest value as the value of the highest value as the worst and the best value. And contrary to the variable with the mean value of the smaller the better, then the highest value as the value of the ugliest and the lowest value as the best value. Calculating the value of the $(\mathrm{Nh})$ of each variable were obtained from the multiplication of normal weight $(\mathrm{BN})$ with effectiveness $(\mathrm{Ne})$. Then add up the value of the 
results of all the variables, and selected the best combination of treatments that has a value $\mathrm{Nh})$ the highest.

\section{Results and Discussion}

\subsection{Research Data}

\begin{tabular}{ccrrrr}
\hline Perlakuan & \multicolumn{5}{c}{ Rerata Hasil } \\
\cline { 2 - 6 } & Amilosa & Pati & \multicolumn{1}{c}{ Viskositas } & Gula Reduksi & Daya Larut \\
\hline S1KA & 12.59 & 64.89 & 641.00 & 4.76 & 51,68 \\
S1KB & 7.92 & 65.36 & 905.33 & 3.59 & 66,42 \\
S1KC & 11.39 & 66.58 & 1005.33 & 2.63 & 82,58 \\
S1KD & 11.61 & 65.07 & 1299.66 & 0.88 & 80.84 \\
S2KA & 12.14 & 64.51 & 1166.33 & 4.24 & 46,06 \\
S2KB & 8.84 & 64.84 & 1283.33 & 3.48 & 68,38 \\
S2KC & 15.13 & 66.06 & 1314.67 & 2.01 & 80,91 \\
S2KD & 18.43 & 65.36 & 1414.65 & 0.40 & 74,26 \\
S3KA & 17.75 & 64.36 & 215.66 & 3.07 & 56,44 \\
S3K2 & 8.93 & 64.92 & 420.33 & 1.12 & 72,29 \\
S3K3 & 19.58 & 65.00 & 520.33 & 0.27 & 91,99 \\
S3KD & 21.36 & 64.31 & 667.00 & 0.16 & 89,99 \\
\hline
\end{tabular}

\subsection{Amylose Content}

Levels of amylose test results ranged from $7.92 \%$ in the treatment of heating temperature 40 ${ }^{\circ} \mathrm{C}$ for 5 minutes with $0.20 \% \mathrm{NaHSO} 3$ concentration. While the highest amylose content of $21.36 \%$ for the treatment of heating temperature $60{ }^{\circ} \mathrm{C}$ for 5 min with a solution of $\mathrm{NaHSO}_{3}$ concentration of $0.40 \%$. This is consistent with research Soebagio et al. (2007) where the influence of high temperatures with limited water content of the physical modification of starch initially increased amylose levels and then drop back optimum, this was due to the termination of glucoside bonds in amylose chains during heating takes place, the constitute the majority of amorphous regions.

The results of analysis of variance showed that the heating temperature and the concentration of $\mathrm{NaHSO}_{3}$ solution was highly significant $(\mathrm{P}<0.01)$ the levels of amylose starch Bruguiera gymnorhiza (L.) Lamk were extracted, there is also a highly significant interaction $(\mathrm{P}<0.01)$ between temperature heating concentration the amylose content as shown in Figure 1. 


\section{Macrothink}

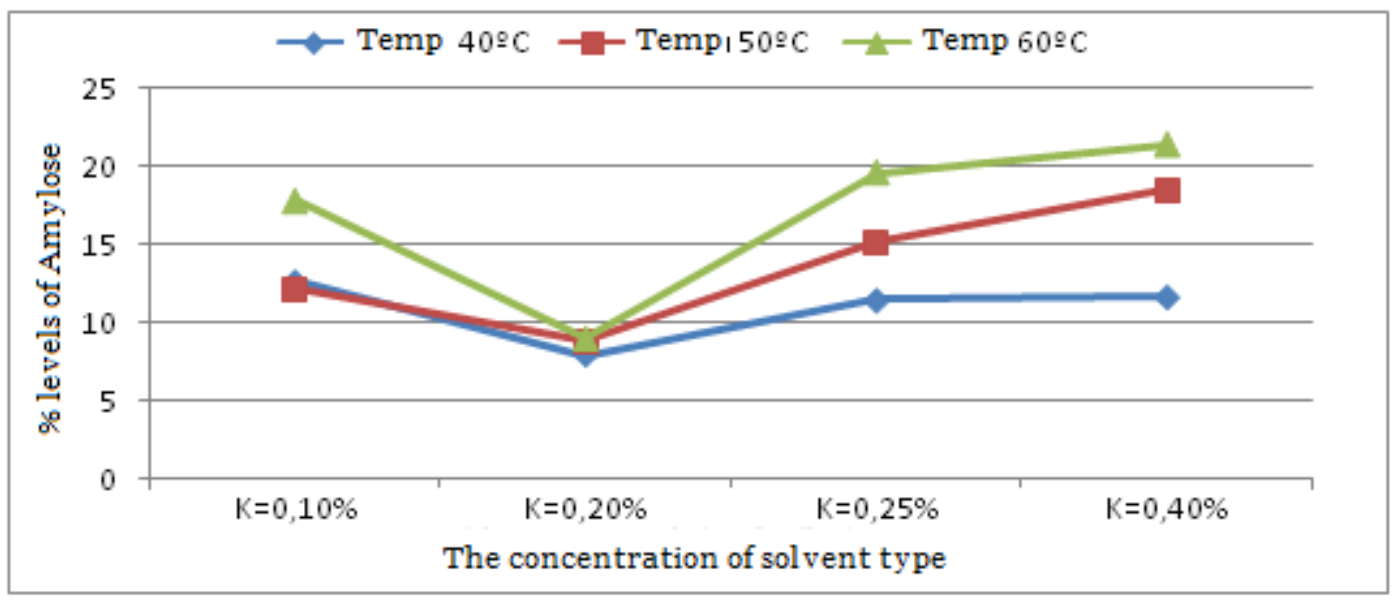

Figure 1. Graph relations treatment of amylose content

\subsection{Starch Content}

Starch content is one of the quality criteria for wheat, both as food and non-food. hipocotyl Bruguiera gymnorrhiza grade starch in very high amounts in wheat hipocotyl Bruguiera gymnorrhiza $63.04 \%$, while the starch content of starch in the form of extracts according to the results of testing the treatment ranging from $64.31 \%$ in the heating temperature $60{ }^{\circ} \mathrm{C}$ for 5 minute with a solution of $\mathrm{NaHSO}_{3}$ concentration of $0.40 \%$. And the highest starch content of $66.58 \%$ in the treatment of heating temperature of $40{ }^{\circ} \mathrm{C}$ for 5 minutes with $0.25 \%$ $\mathrm{NaHSO}_{3}$ concentration. This shows that the differences are not too large, the higher the heating temperature drops more levels comparable to the higher starch concentration and starch content increases in the concentration of $0.25 \%$ for all the heating temperature treatment. This shows that the concentration of $\mathrm{NaHSO}_{3} 0.25 \%$ at $40^{\circ} \mathrm{C}$ heating temperature is an optimum point. This is consistent with research Yusraini (2007).

The results of analysis of variance showed that the heating temperature and the concentration of $\mathrm{NaHSO}_{3}$ solution was highly significant $(\mathrm{P}<0.01)$ to the starch content of starch extracts of Bruguiera gymnorhiza (L.) Lamk, there is also a highly significant interaction $(\mathrm{P}<0.01)$ between temperature heating concentration the starch content as shown in Figure 2. 


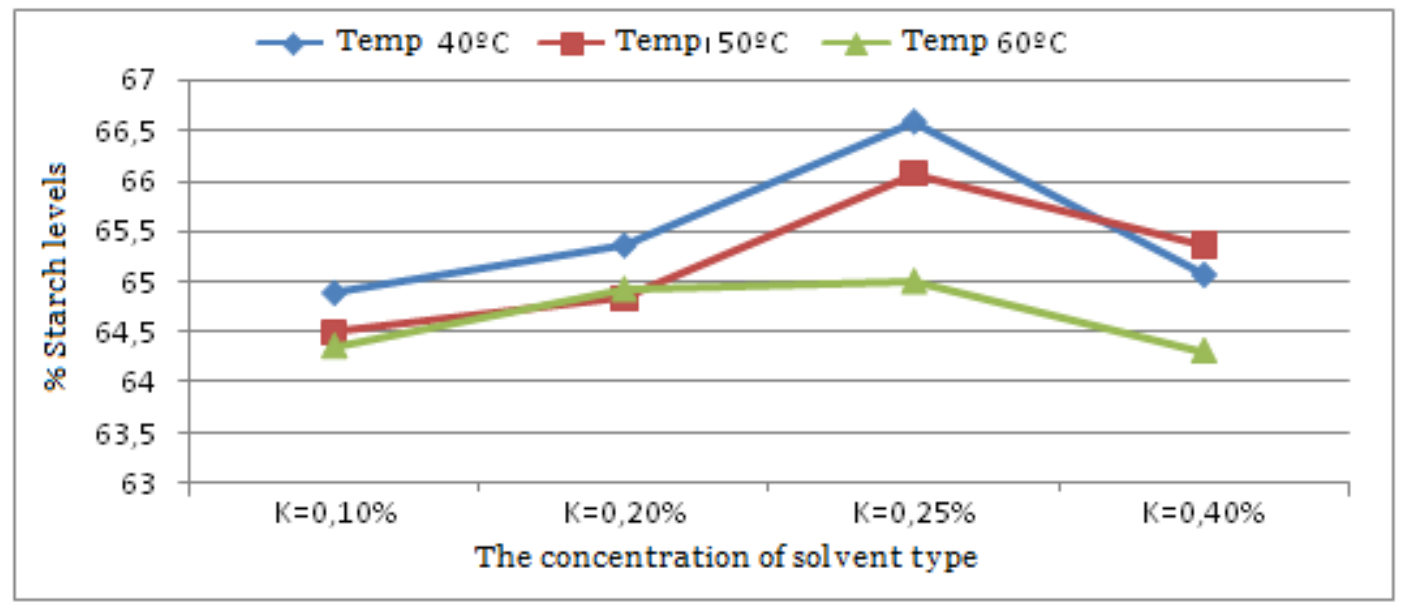

Figure 2. Graph relations treatment of starch content

\subsection{Viscosity}

Mean viscosity values in this study ranged between $215.66 \mathrm{cP}-1414 \mathrm{cP}$. Viscosity values increase with increasing heating temperature and the increase is proportional to the concentration levels of amylose. The higher levels of amylose, the value will be higher and the viscosity decreases with decreasing amylose as heating temperature is too high. This is consistent with research Whitt (2002) who reported that amylopectin has a stronger effect on viscosity due to the branched structure and more open compared to amylose, amylopectin which can thicken pasta starch as the temperature rises. Also according to Chen (2003), measuring the tendency to experience retrogradasi starch can be done by two methods: by measuring freezethaw stability and viscosity ratio measurements setback pasta. Syneresis occurs at the time of repeated freeze-thaw cycles showed an increase in intermolecular hydrogen bonding between amylose to amylose, amylopectin with amylose and amylopectin with amylopectin. Meanwhile, the setback paste viscosity showed a tendency retrogradasi happened because amylose molecules more easily exposed to water and prone to recrystallization than amylopectin

The results of analysis of variance showed that the heating temperature and the concentration of $\mathrm{NaHSO}_{3}$ solution was highly significant $(\mathrm{P}<0.01)$ to the value of the viscosity of the starch extracts of Bruguiera gymnorhiza, there is also a highly significant interaction $(\mathrm{P}<$ 0.01 ) between temperature heating concentration the starch viscosity values as shown in Figure 3. 


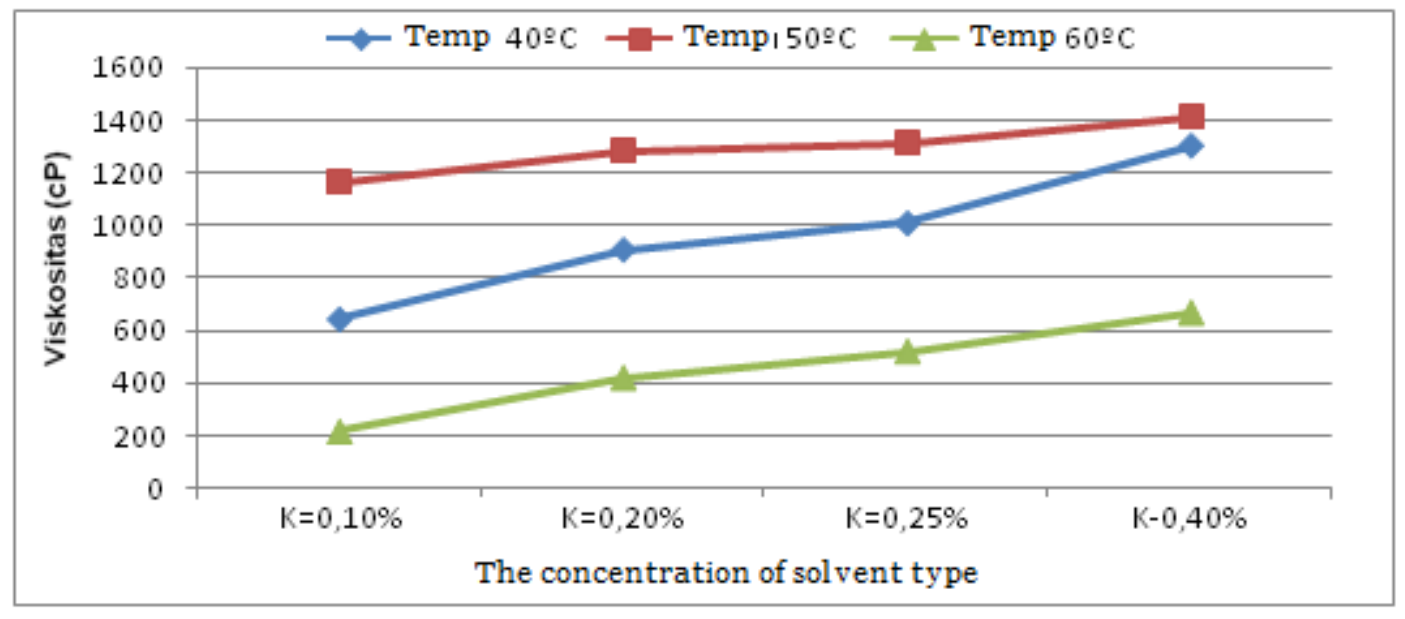

Figure 3. Graph relations treatment of viscosity

\subsection{Solubility}

Mean value of solubility in this study ranged from $46.06 \%-91.99 \%$, ie the treatment of heating temperature $50{ }^{\circ} \mathrm{C}$ for 5 minute with a concentration of $0.10 \%$ is the lowest and the highest is in the heating temperature $60{ }^{\circ} \mathrm{C}$ for 5 minute with a solution concentration $0.25 \%$. It is directly proportional to amylose content and viscosity values are likely to increase in accordance with increasing temperature and increased concentration. Solubility also increased from a temperature of $40{ }^{\circ} \mathrm{C}$ to a temperature of $60{ }^{\circ} \mathrm{C}$. This is because the hydrogen bonds in the starch has not been interrupted or lost during the heating takes place in a relatively short period of 5 minutes. If the heating lasts for a long time then it will lead to the loss of free hydroxyl solubility little starch, so the starch will also be difficult to absorb the water and there is no development (swelling) that is too large. Thus, the fewer the number of hydroxyl groups of the lower molecular starch granules absorb water capacity (Herath, 2009).

The results of analysis of variance showed that the heating temperature and the concentration of $\mathrm{NaHSO}_{3}$ solution was highly significant $(\mathrm{P}<0.01)$ the solubility of the starch extracts of Bruguiera gymnorhiza (L.) Lamk, there is also a highly significant interaction $(\mathrm{P}<0.01)$ between the heating temperature of the solution concentration solubility of starch as shown in Figure 4. 


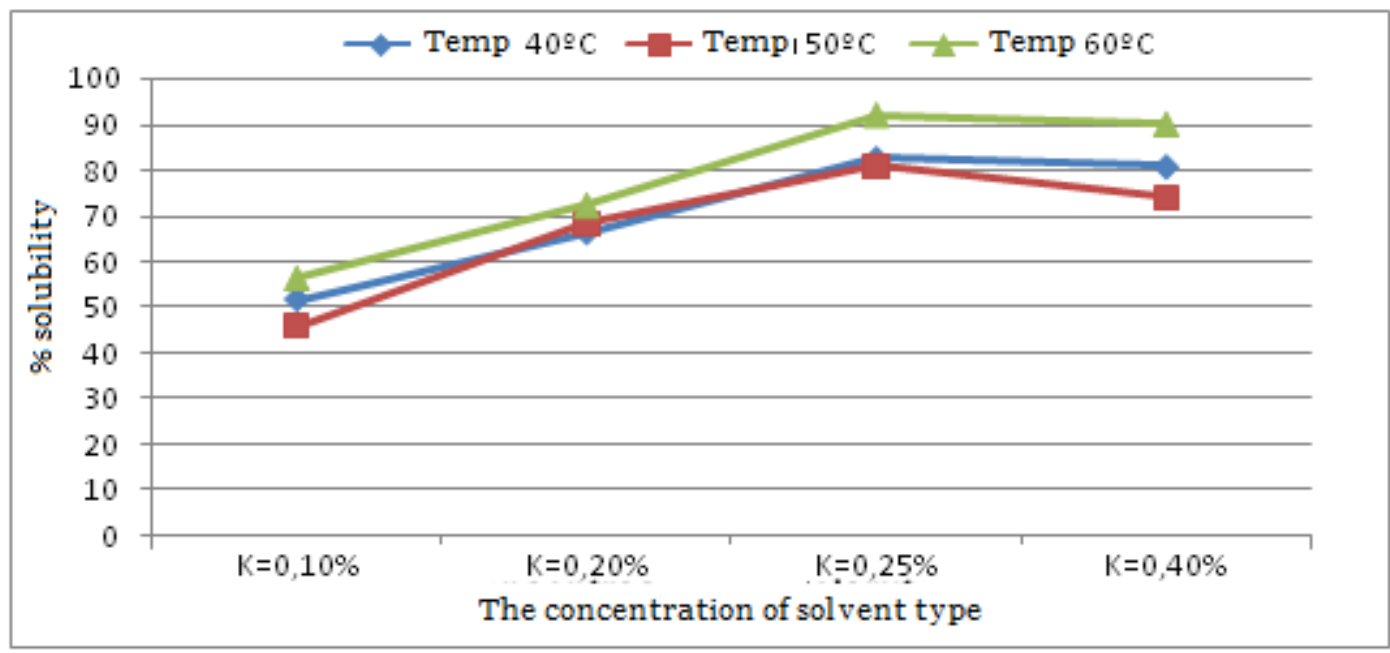

Figure 4. Graph relations treatment of solubility

\subsection{Reduction Sugar}

Mean value of reducing sugar in this study ranged from $0.16 \%-4.76 \%$ ie the treatment of heating temperature $60{ }^{\circ} \mathrm{C}$ for 5 minute with a concentration of $0.40 \%$ is the lowest and the highest is at heating temperature $40{ }^{\circ} \mathrm{C}$ for 5 minute with a solution concentration $0.10 \%$. This result indicates that the reduction of sugar levels low among all treatments. This is because the process of decomposition of polysaccharides halted by the heating process. If the initial sampling until the treatment process pause is long enough, there will be a polysaccharide decomposition, causing increased levels of reducing sugar. This is consistent with the study reported by Poedjiadi (1994) Sugar reduction is the result of the decomposition of polysaccharides shape in the form of glucose and fructose which have reactive groups to carry out the reaction. The reactive groups such as aldehyde or ketone-free. Reducing sugar has the ability to reduce $\mathrm{Cu}^{2+}$ (cupric ions) into $\mathrm{CU}^{+}$(ion cupro). Ion cupro arsenomolibdat reagent is able to transform into a stable blue complex.

The results of analysis of variance showed that the heating temperature and the concentration of $\mathrm{NaHSO}_{3}$ solution was highly significant $(\mathrm{P}<0.01)$ reduction of sugar to starch extracts Bruguiera gymnorhiza (L.) Lamk, there is also a highly significant interaction $(\mathrm{P}<0.01)$ between temperature heating concentration starch to sugar reduction as shown in Figure 5. 


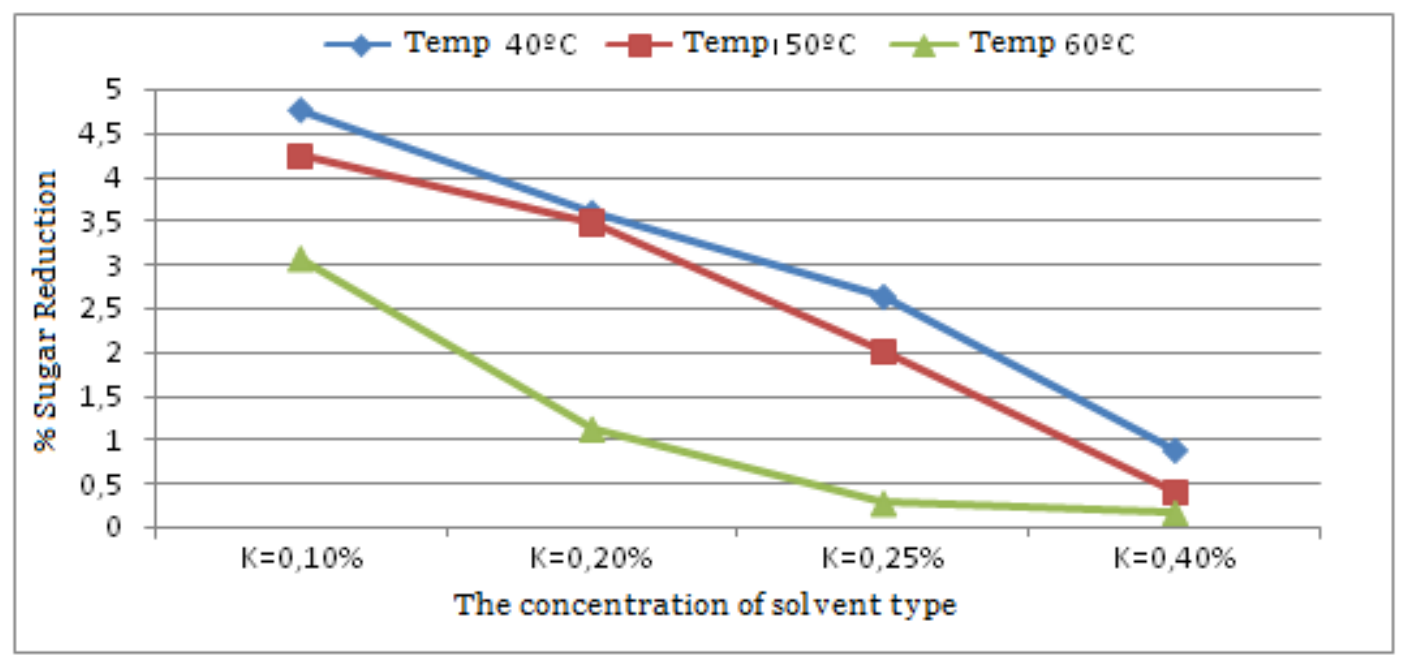

Figure 5. Graph relations treatment of sugar reduction

\subsection{Best Treatment}

Determining the best treatment using effective index method (De Garmo) method is performed on the parameters used in this study as for the parameters of the amylose content, starch content, solubility, viscosity and reducing sugar. Calculation results showed the combination best treatment on various parameters of the research showed that the combination treatment of concentrated solutions of $\mathrm{NaHSO}_{3} \quad 0.25 \%$ and the heating temperature $60{ }^{\circ} \mathrm{C}\left(\mathrm{KCS}_{3}\right)$ were the levels of amylose $19.58 \%$, starch content $65.00 \%$, viscosity $520.33 \mathrm{cP}$, reducing sugar $0.27 \%$ and solubility $91.99 \%$.

\section{Conclusion}

From the research it can be concluded that the greater the concentration of sodium bisulfite solution, the amylose content, reducing sugar content, solubility and viscosity of the starch getting up. That the longer the heating time will result in a decrease of starch, amylose levels increase, reducing sugar, solubility and viscosity. Interaction of treatment occurs in operating conditions to produce the optimum heating temperature is $60{ }^{\circ} \mathrm{C}$, for $5 \mathrm{~min}$ at a concentration of sodium bisulfite $0.60 \mathrm{~g} / \mathrm{l}$. The resulting starch can be recommended as a base for food and pharmaceutical industry.

\section{Reference}

Association of Official Analytical Chemists. (1984). AOAC (14th ed), Ins Arington Virginia.

AOAC. (1990). Official Methods of Analysis of the Association of Official Analytical Chemists (Volume 1, 15th Edition) Washington.

AOAC. (1998). Official Methods of Analysis of the Association Analytical Chemistry, Inc., Washington DC.

Bello-Pe'rez, L. A., Religion-Acevedo, E., Sa'nchez-Herna'ndez, L., \& Paredes-Lo'pez, O. 
(1999). Isolation and Partial Characterization of Banana Starches. Journal of Agricultural and Food Chemistry, 47, 854-857. http://dx.doi.org/10.1021/jf980828t

Betancur-Ancona, D., Peraza-Mercado, G., Ordon ez-Moguel, Y., \& Fuertes-Blanco, S. (2004). Physicochemical characterization of Lima bean (Phaseolus lunatus) and Jack bean (Canavalia ensiformis) fibrous residues. Food Chemistry, 84, 287-295. http://dx.doi.org/10.1016/S0308-8146(03)00213-9

Chen, X. B., \& Duan, W. Y. (2003). Capillarygarvity waves due to an impulsive disturbance. Proc. 18th Intl Workshop on Water Waves and Floating Bodies, Carry-Le-Rouet (France).

De Garmo, E. D., Sullivan, W. G., \& Canada, J. R. (1984). Engineering Economy. MacMillan Publishing Company, New York.

FAOSTAT. (2002). FAO Database. Food and Agriculture Organisation of the United Nations. Rome, Italy, 19.2.

Fortuna, James de. (2005). Mangrove Fruit Found In Food Basic. Retrieved from http://www.Tempo interaktif.com.Diakses 2011.

Herath, D. (2009). Sago Starch Modification by Heat Moisture Treatment Technique (HMT) and Its Application in Improving Quality of vermicelli. Master's degree. Bogor Agricultural University. Bogor.

Irawan, M. A. (2007). Carbohydrates. Sports Science Brief, 1(3). www.pssp.lab.com accessed 2011.

Juliano, B. O. (1971). A simplified assay for milled rice amylose measurement. Journal of Cereal Science Today., 16, 334-336

Juliano, B. O., \& Kongseree. (1968). Physic Chemical Properties of Rice Grain and Starch from line differing in amylose content and gelatinization temperature. J. Agric and Food Chem, 20, 714-717.

Pentury, M. H. (2009). Kajian Potensi Hutan Mangrove Dalam Upaya Penyediaan Pangan Buletin Dinamika Kopertis Wilayah XII, 2, 17-21.

Purnobasuki, H. (2011). Potential as Alternative Food Fruit Mangrove. Retrieved from http://herypurba-fst.web.unair.ac.id/

Pereira, R. C. (2008). Relationship between structural and biochemical characteristics and texture of corn grains. Genetics and molecular research, 7, 498-508. http://dx.doi.org/10.4238/vol7-2gmr446

Poedjiadi. (1994). Fundamentals of Biochemistry. Jakarta: UI Press.

Richana, N., \& Titi, S. C. (2004). Characterization of Physicochemical Properties of Wheat flour starch from tubers and canna bulbs, suweg, ubikelapa and gembili. Postharvest Journal, $1(1), 29-37$

Sadana. D. (2007). Fruit aibon in East Biak Contain High Carbohydrate. Government Official 


\section{Macrothink}

Website of Biak Num for news_htm

Soebagio, B., Sriwidodo, \& Aditya, S. A. (2007). Testing of Seed Starch Physicochemical properties Durian (Durio zibethinus Murr.,) Natural And Modified By Acid Hydrolysis. Journal. Padjadjaran University.

Waliszewskia, K. N., Maria, A. A., Lui, A. B., \& Jo'se, A. M. (2003). Changes of banana starch by chemical and physical modification of Carbohydrate Polymers, 52, 237-242

Wanma, A. (2007). Utilization of Mangrove Forests (Bruguiera gymnorhiza) L. Lamk For Producing Materials Carbohydrates, Soil Conservation Bulletin tongue.

White, P. J., Abbas, I. R., \& Johnson, L. A. (1989). Freeze thaw stability and Refrigerated storage retrogradation of starches. Starch/Starke, 41, 176. http://dx.doi.org/10.1002/star.19890410505

Yusraini, E., Purwiytno, H., \& Ferry, K. (2007). Characterization of the production process from starch maltodextrin banana (Musa sp) enzymatically with $\alpha$-amylase. Scientific journal, $30(2), 159-168$.

\section{Copyright Disclaimer}

Copyright reserved by the author(s).

This article is an open-access article distributed under the terms and conditions of the Creative Commons Attribution license (http://creativecommons.org/licenses/by/3.0/). 